J. Lake Sci. (湖泊科学), 2015, 27(1): 86-93

http: //www. jlakes.org. E-mail : jlakes@niglas.ac.cn

(C) 2015 by Journal of Lake Sciences

\title{
珠江流域西江支流贺江水体硅藻群落结构、分布和评估"
}

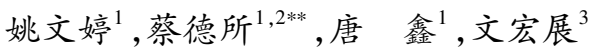 \\ (1: 三峡大学水利与环境学院,宜昌 443002) \\ (2: 广西水利电力勘测设计研究院, 南宁 530023 ) \\ (3: 广西水环境监测中心, 南宁 530023)
}

摘 要: 综合运用 TWINSPAN 数量分类和 DCA 排序方法评估了贺江流域硅藻群落, 结合硅藻生物指数 (IBD)、硅藻属指 数 $(I D G)$ 、硅藻营养化指数 $(T D I)$ 和特定污染敏感指数 (IPS) 对其结果进行进一步验证. 结果显示, TWINSPAN 将贺江流 域的 38 个样点分为 4 组, 且群落 $\mathrm{I}$ 到群落 $\mathrm{V}$ 其生境质量逐渐变得单一, 人为干扰程度逐渐加大; 划分的四组群落在 DCA 排序图上有明显的界限, 依据 Van Dam 硅藻生态指示意义, 水环境污染程度从群落 I 到群落 IV 逐渐加剧, 有争议的样点 $7 、 8$ 和 24 在 DCA 排序图上也倾向于群落 III. 4 种硅藻指数都是显著相关的, 但 IBD、IPS、IDG 在硅藻群落的箱型图中明显 呈现出合理的趋势. 以上研究表明, 划分的硅藻群落较好地反映了贺江流域的生态质量, IBD、IPS、IDG 适合于贺江流域生 物监测与评价.

关键词: 硅藻群落;TWINSPAN 分类;DCA 排序; 硅藻指数;贺江;西江; 珠江流域

\section{Distribution and evaluation of diatom community in Hejiang River, a branch of Xijiang Riv- er, Pearl River basin}

YAO Wenting ${ }^{1}$, CAI Desuo ${ }^{1,2}$, TANG Xin ${ }^{1} \&$ WEN Hongzhan ${ }^{3}$

(1: College of Hydraulic and Environmental Engineering, China Three Gorges University, Yichang 443002, P. R. China)

(2: Guangxi Water and Power Design Institute, Nanning 530023, P. R. China)

(3: Water Environment Monitoring Center of Guangxi Province, Nanning 530023, P. R. China)

Abstract: The diatom communities of Hejiang River, a branch of Xijiang River, Pearl River basin were evaulated by means of twoway indicator species analysis and detrended correspondence analysis. The diatom indexes of Generic Diatom Index (IDG), Biological diatom index $(I B D)$, Specific Pollution sensitivity Index (IPS) and Trophic Diatom Index (TDI) were then further used to validate the conclusion. According to TWINSPAN, the 38 sampling sites of Hejiang River were classified into 4 types, the quality of ecological habitat and human disturbance were getting worse and worse from community I to community IV ; the obvious boundaries of four communities existed on DCA ordination diagram, the ecological value of Van Dam showed that water environmental pollution gradually increased from I to $\mathrm{IV}$, the controversial samples of 7,8 and 24 tended to community III on DCA ordination diagram. The results indicated that the divided diatom communities can better reflect the ecological quality, in addition, IBD, IPS, IDG can be applied for monitoring and evaluating rivers in Hejiang River.

Keywords: Diatom community; two-way indicator species analysis; detrended correspondence analysis; diatom indexes; Hejiang River; Xijiang River ; Pearl River basin

硅藻作为水生态系统中的初级生产者, 具有很高的繁殖率和很短的生命周期, 对水体中的各种环境因 子(酸堿度、重金属、富营养化等) 和生态环境的变化能够快速响应, 主要体现在硅藻群落的变化上, 如在较 清洁的水体中, 清洁指示种如曲壳藻 (Achnanthes sp.) 等所占比例较大, 而当营养盐浓度较高时, 耐污性藻属

* 国家自然科学基金项目 (40971280,30870345) 资助. 2014-02-24 收稿;2014-04-15 收修改稿. 姚文婷 (1990 ), 女, 硕士研究生;E-mail:602632774@ qq. com.

** 通信作者;E-mail:caidesuo@vip163.com. 
如菱形藻 (Nitzschia sp.) 的丰度会增加 ${ }^{[1]}$. 在此基础上,形成了数十种河流硅藻指数, 广泛使用的有特定污染 敏感指数 ( specific pollution sensitivity index, IPS)、硅藻生物指数 (biological diatom index, IBD)、硅藻属指数 ( generic diatom index, $I D G$ )、硅藻营养化指数 (trophic diatom index, $T D I)^{[2-5]}$, 这些指数在一定程度上可以反 映河流生态质量的变化; 同时, 硅藻群落相对于参考点的变异程度用于评价水生态系统的健康程度和恢复 状况在欧盟以及美国广泛使用 ${ }^{[6]}$.

群落研究的常见方法是数量分类以及排序, 可以揭示群落之间的内部联系及与环境因子之间的生态关 系. 国内外广泛使用的数量分类方法为双向指示种分析 (two-way indicator species analysis, TWINSPAN), 通 过数量分类指示种来划分群落; 排序方法有除趋势对应分析 (detrended correspondence analysis, DCA) 以及 典范对应分析 (canonical correspondence analysis, CCA) 等.

贺江流域主要流经广西壮族自治区贺州市, 是珠江流域西江的主要支流, 漓江的姐妹江, 古时是主要的 水上交通要道. 由于流域的水能开发和支流沿岸采矿、采砂等人类活动的破坏, 使其出现水质恶化、重金属 污染以及断流等一系列环境问题. 本文采用 TWINSPAN 以及 DCA 的分析方法, 对贺江流域的硅藻群落进行 数量分类以及排序, 且与硅藻指数进行比较, 以期为该流域的生态质量以及环境保护提供生物学依据.

\section{1 材料与方法}

\section{1 贺江流域概况及采样点}

贺江流域面积为 $11536 \mathrm{~km}^{2}$, 全长 $352 \mathrm{~km}$, 其上游富川江发源于富川瑶族自治县麦岭乡的茗山, 经贺江 后在梧州汇人西江干流, 其主要的支流有白沙河、西湾河、马尾河、大宁河、东安江, 其中支流最大的为东安 江, 全长 $168 \mathrm{~km}$. 研究中, 采样点覆盖了贺江的干流以及一级支流, 共 38 个样点, 分布点见图 1.

\section{2 样品采集与处理}

于 2013 年 6 月对贺江流域进行硅藻采样. 采样基质选取能抵抗水流、地势开阔且无树荫遮蔽的石头,用 干净的牙刷刷取石头的向阳面, 装人容量瓶中用甲醛固定, 如采样点附近无石头, 可以选择挺水植物代替. 样品经过氧化氢和浓盐酸消解, 封片胶封片, 光学显微镜下采用 1000 倍油镜检验、鉴定, 视野内所有硅藻及 破损面积不超过 $1 / 4$ 的样品都要进行鉴定和计数, 每个玻片鉴定总数大于 400 , 鉴定依据 Krammer 和 LangeBertalot 体系 ${ }^{[7]}$ 和 $\left\langle\right.$ 中国淡水藻志》 ${ }^{[8-9]}$.

\section{3 数据处理}

进行排序以及数量分类时, 剔除丰度小于 $5 \%$ 的硅藻种类, 应用 CANOCO 软件进行 DCA 分析, DCA 分 析的物种数据进行开平方处理, 并在 CANODRAW 中完成排序作图, PC-ORD 进行 TWINSPAN 分析, 相关指 数计算应用 OMNIDIA 软件完成,使用 SPSS 18.0 软件完成箱型图的绘制.

\section{2 结果与分析}

\section{1 样点 TWINSPAN 数量分类结果}

贺江流域 38 个样点中, 样点 S2 的采样基质为水草, 其余为石头, 共鉴定出 154 种硅藻, 其中丰度大于 $5 \%$ 的硅藻种类有 51 种, 以曲壳藻属 (Achnanthes sp.)、舟形藻属 (Navicula sp.)、菱形藻属 (Nitzschia sp.) 为 主. 结合采样点周围的生境、底质和两岸的人类干扰程度, 利用 TWINSPAN 对硅藻群落进行数量分类, 将 38 个样点分为 4 类, 分类结果见图 2.

$\mathrm{I}$ : 硅藻优势种为 Achnanthidium minutissima、Achnanthes biasolettiana、Cocconeis placentula var. lineata、 Melosira varians、Navicula gregaria, 包括样点 $1 、 3 、 5 、 6 、 12 、 22 、 26 、 34 、 36 、 37$, 多分布于贺江的上游(无水电站 的干扰)、贺江支流大宁河; 采样底质多为鹅卵石、碎石和砂石; 生境较复杂, 河两岸有水草、枯枝落叶、倒木 等;渠道化较少,维持正常的河道模式;河岸两侧农田居多.

II : 硅藻优势种为 Achnanthidium minutissima、Nitzschia palea、Achnanthes biasolettiana、Cocconeis placentula var. lineata、Melosira varians、Gomphonema parvulum、Cyclotella atomus、Navicula erifuga 、Fragilaria virescens, 包括 样点 $4 、 7 、 8 、 9 、 24 、 27 、 28 、 29 、 30 、 35$, 主要分布于贺江干流、下游与西江交汇处; 鹅卵石、碎石和砂石等基质占 $25 \% \sim 50 \%$, 其余为细砂等沉积物; 生境较复杂, 河两岸有水草、枯枝落叶、倒木等; 渠道化出现较少, 水电站 


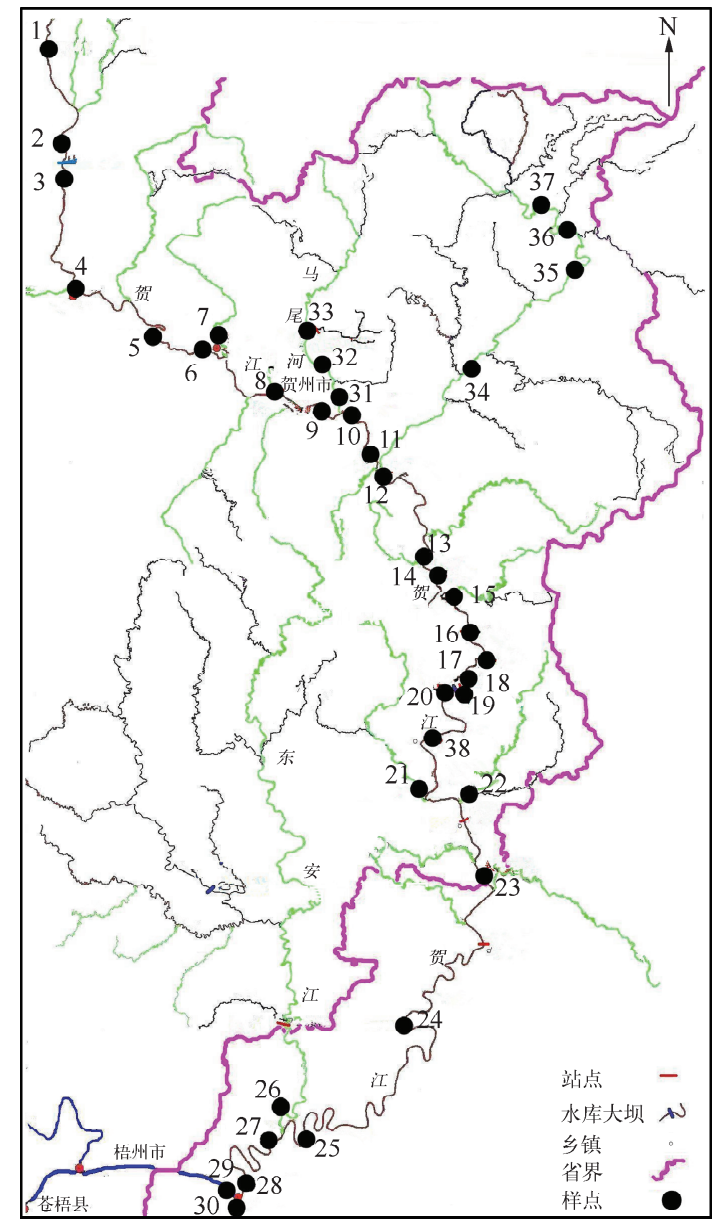

图 1 贺江流域硅藻采样点

( 1 : 富阳镇; : 龟石大坝上; 3 : 龟石大坝下 $; 4$ : 钟山县 ; 5 : 羊头镇; 6 : 黄石村 ; 7 : 西湾河口; 8 : 贺州水文站; 9 : 大水排; 10 : 小水; 11 : 贺街; 12 : 大宁河口; 13 : 步头 ; 14 : 库 $1 ; 15$ : 库 2 ; 16 : 库 $3 ; 17$ : 库 $4 ; 18$ : 库 $5 ; 19$ : 合面狮大坝上; 20 : 合面狮大坝下; 21 : 林洞河口; 22 : 沙冲河 口;23:扶隆浮桥; 24 : 都平镇; 25 : 大洲村; 26 : 东安江河口;27: 上百吉;28: 封开县;29:大 旺村;30:川江镇;31: 马尾河口;32: 龙岩寨;33: 新村;34: 黄洞; 35 : 大宁镇; 36 : 北平村;

37 : 松木龙; 38 :信都水文站)

Fig. 1 The map of diatom sampling sites in Hejiang River

上下游一定范围内的河岸由铁丝和混凝土固定; 人类干扰较大, 河岸两侧农田居多.

III : 硅藻优势种为 Nitzschia palea、Gomphonema parvulum、Achnanthidium minutissima、Cyclotella atomus、 Nitzschia fonticola, 包括样点 $13 、 20 、 21 、 25 、 32 、 38$; 鹅卵石、碎石和砂石等基质占 $25 \% \sim 50 \%$, 其余为细砂等沉 积物; 生境较单一, 只出现一种或两种生境; 渠道化出现较少; 人类干扰较大, 河岸两侧农田居多.

IV : 硅藻优势种为 Nitzschia palea、Gomphonema parvulum、Nitzschia intermedia、Nitzschia fonticola、Achnanthes exiguum、Aulacoseira ambigua, 包括样点 $2 、 10 、 11 、 14 、 15 、 16 、 17 、 18 、 19 、 23 、 31 、 33$; 碎石、鹅卵石、大石少于 $25 \%$, 其余为细砂等沉积物; 主要为河道型水库, 生境较为单一; 河岸两侧为农田或是废弃的耕作土壤. 群落 III 与 IV 的样点集中在贺江流域的中游, 主要包括支流马尾河以及合面狮水电站上下游附近.

\section{2 样点 DCA 排序结果}

DCA 分析结果可以较好地反映出 TWINSPAN 的数量分类结果 (图 3 ). TWINSPAN 数量分类的结果在 


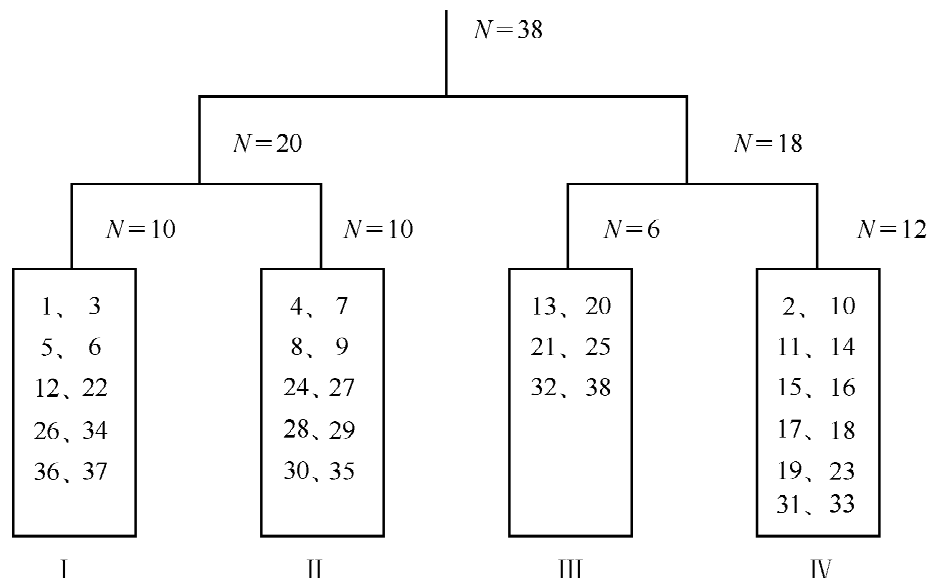

图 2 硅藻群落 TWINSPAN 分类结果

Fig. 2 The classification of diatom communities by TWINSPAN

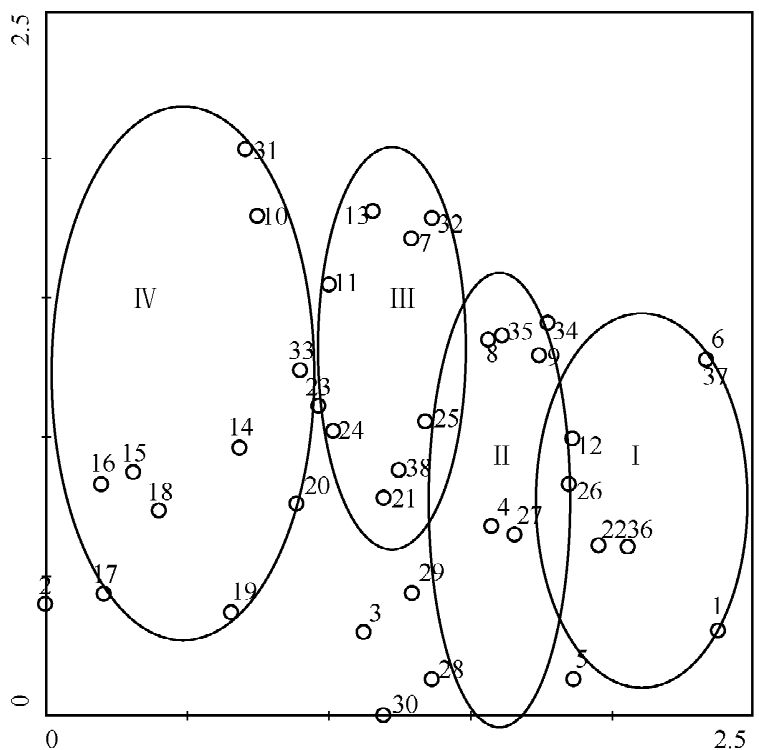

图 3 硅藻群落 38 个样点的 DCA 排序图

Fig. 3 DCA ordination diagram of 38 sampling sites of diatom communities

DCA 排序图上均有分布范围和界限, 少数样点 (样点 $2 、 3 、 30$ ) 除外, 从图中也可以得知群落 I 与群落 II 相似 性较高, 群落 II 与群落 III 也具有一定的相似性, 同理群落 III 与群落 IV 也有一定的相似性. 依据 $\operatorname{Van} \operatorname{Dam}^{[10]}$ 的 硅藻生态指示意义,各个硅藻群落所反映的生态意义也不同.

群落 I :Achnanthidium minutissima、Achnanthes biasolettiana 和 Cocconeis placentula var. lineata 主要出现在 清洁、营养水平较低的水体中, 该群落中占多数的为曲壳藻属 (Achnanthes sp.), 虽然曲壳藻属指示的生态意 义较宽广,但总体代表着较低的污染水平, Melosira varians 常出现在富营养化的水体中,该种类为样点 12 的 第二优势种.

群落 II : 绝大多数点的优势种仍为 Achnanthidium minutissima 和 Achnanthes biasolettiana, 样点 7、8、24 的 优势种为 Nitzschia palea, 为强有机污染和富营养化的指示种, Cyclotella atomus、Melosira varians 也是常见的 富营养化的指示种. 
群落 III : 所有样点的第一优势种均为 Nitzschia palea, 第二优势种主要为 Gomphonema parvulum, 其也为富 营养化的指示种.

群落IV : 优势种主要为 Nitzschia palea, 其余为 Gomphonema parvulum、Nitzschia intermedia、Nitzschia fontico$l a$, 均为有机污染以及富营养化的指示种, 主要以菱形藻属居多, 而绝大多数菱形藻都指示一定程度的污染. 因此 4 个硅藻群落的水质污染程度从群落 I 到群落 $\mathrm{IV}$ 逐渐增加.

\section{3 硅藻指数箱型图分析}

选取 IPS、IBD、IDG、TDI 指数进行回归分析以及与硅藻群落之间进行分析. 从表 1 可知 4 种硅藻指数的 相关性极显著 $(P<0.01)$. 由箱型图了解到, IPS、IDG、IBD 的值从群落 I 到群落 $\mathrm{V}$ 呈下降趋势, 而 $T D I$ 呈波 动变化趋势 (图 4). 相较 $T D I$ 而言, $I P S 、 I D G 、 I B D$ 更加适合评价贺江流域的水生态质量, 这也从指数方面验 证了从群落 I 到群落 $\mathrm{IV}$ 的水质污染程度.

表 1 硅藻指数之间的 pearson 相关系数 $(n=38)$

Tab. 1 The pearson correlative coefficients among four diatom indexes

\begin{tabular}{ccccc}
\hline 硅藻指数 & $T D I$ & $I D G$ & $I P S$ & $I B D$ \\
\hline$T D I$ & 1 & - & - & - \\
$I D G$ & $0.763^{* *}$ & 1 & - & - \\
$I P S$ & $0.786^{* *}$ & $0.937^{* *}$ & 1 & - \\
$I B D$ & $0.819^{* *}$ & $0.857^{* *}$ & $0.928^{* *}$ & 1 \\
\hline
\end{tabular}

$* *$ 表示相关系数达到极显著水平 $(P \leqslant 0.01$, 自由度 38$)$.

\section{3 讨论}

群落 I 样点 12 的优势种为 Melosira varians, 在排序图上较倾向于群落 II , 呈现一定程度的富营养化, 其 原因是采样点附近有大片的蔬菜基地, 农药和杀虫剂普遍使用; 样点 7、24 在 TWINSPAN 图上被划分在群落 II 里面, 而在 DCA 排序图上属于群落 III, 从其硅藻组成看, 其优势种的组成倾向于群落 III, 从分布点看, 样点 7 位于贺州市区, 样点 24 为都平镇, 都是人口密集、城市和农业发达的区域, 对美国以及西班牙河流的相关 研究也表明城市和农业利用面积会影响硅藻群落分布 ${ }^{[11-12]}$, 主要是改变了河流原有的自然环境、水流方向 以及水体各项理化指标 ${ }^{[13]}$; 群落 III 与群落 $\mathrm{I}$ 的大多数样点在库区, 水库的蓄水作用和工业、生活污水的排 放, 使得营养盐富集, N、P 等的含量上升 ${ }^{[14-16]}$, 从而使富营养化和有机污染的指示种丰度增加. 样点 2 在排 序图上偏离划分的群落, 这与采样点的基质有关, 样点 2 的采样基质为挺水植物, 附着于上面的多为静水硅 藻, 与石头基质相比,由于基质附着条件的异质性,相关分析会产生一定的偏差 ${ }^{[17]}$.

TWINSPAN 数量分类是依据指示种划分的,而 DCA 是依据排序轴的综合信息, 将样方排列在一定的空 间上, 排序轴能反映一定的生态梯度. 由于 DCA 排序分析时并没有引人相关的环境数据, 因此并不能具体反 映出是哪几种因子的相互作用, 但从硅藻优势种和生境质量而言, DCA 排序图的第一轴在一定程度上可以 反映贺江水质或是生态质量的变化. 从样点 $12 、 7 、 8 、 24$ 的 TWINSPAN 数量分类和 DCA 排序可知, 两种方法 结合使用可以精确地划分硅藻群落, 同样的方法也适用于划分其它的群落, 如苏日古嘎等 ${ }^{[18]}$ 采用两种方法 结合现场调查划分了松山自然保护区域的植物群落,对群落保护具有指导意义.

TWINSPAN 数量分类和 DCA 划分的硅藻群落在一定程度上反映了河流生境质量对硅藻群落的影响, 从 群落 I 到群落IV生境质量逐级下降, 栖息地环境变得单一, 人为干扰也越来越严重, 特别是群落 $\mathrm{V}$ 中的样点 主要集中在合面狮水电站上游, 其特征为河道型水库, 且支流马尾河采矿严重, 人为干扰比较厉害; 依据 Van $\mathrm{Dam}^{[10]}$ 的生态分类体系, 水质污染程度从群落 I 到群落 $\mathrm{IV}$ 逐渐增加, 根据广西水环境监测中心提供的水质 监测资料, 支流马尾河到信都水文站这一段, 重金属镉、铊严重超标, 水质处于劣 V 类 (参考国家《地表水环 境质量标准》 ( GB 3838-2002) ), 其它样点的水质都处于 II 、III类水质, 而处于劣 V 类水质的样点绝大多数 都被划分到群落 IV. 相关文献表明 ${ }^{[19-21]}$, 在小流域尺度上, 河流生境质量 ( 诸如河岸带环境、基质、水中悬浮 物、河流形态等) 以及水质影响硅藻群落分布. Pan 等的研究表明河槽形态、河道环境以及河岸带条件是影响 

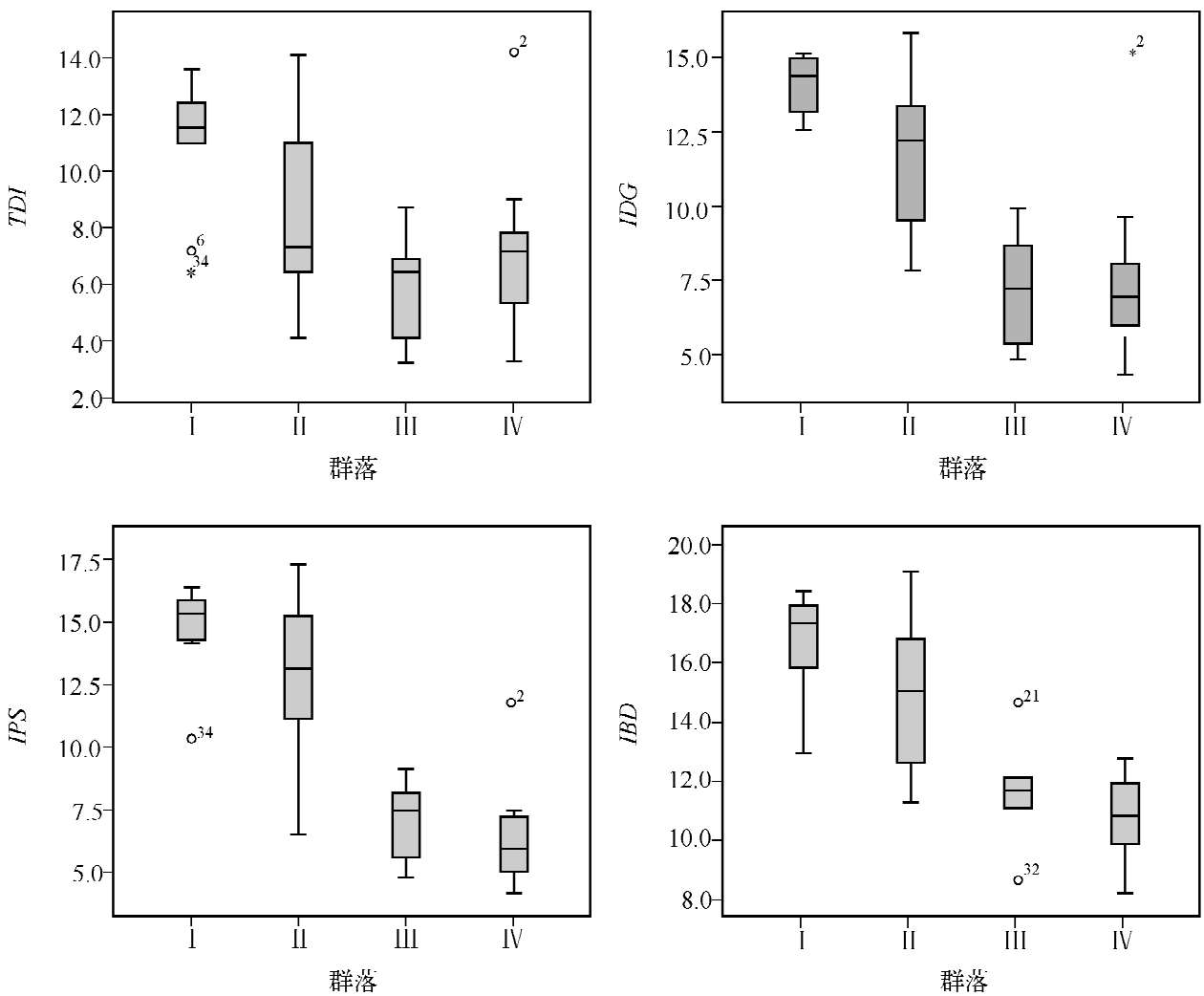

图 44 种硅藻指数的箱型图

Fig. 4 The boxplots of four diatom indexes

California 山谷溪流硅藻群落分布的主要因素 ${ }^{[22]}$; Tang 等发现河流上梯级电站的修建改变了流速、河槽宽 度、 $\mathrm{pH}$ 以及水温, 进而对硅藻的密度以及多样性产生一定的影响 ${ }^{[23]}$; 在大流域尺度上, 土地利用、地形、地质 特征、人为干扰和水质对硅群落分布的影响明显,Urrea 等 ${ }^{[19]}$ 研究发现影响西班牙北部的瓜迪亚纳河流域硅 藻群落分布的两大主要梯度为水质以及地质构造, 流域上游主要为石灰石地质构造, 嗜碱性的硅藻如 Cymbella affinis、Diatoma moniliformis 和 Cymbella cymbiformis 的相对丰度较大;下游主要为硅酸盐构造,嗜酸性的 硅藻如 Cyclotella atomus 的相对丰度较大. 邓培赝等 ${ }^{[24]}$ 采用偏典型相关分析 (CCA) 显示, 硅藻群落的分布是 土地利用、地理因素和水质共同作用的结果.

国内外开发的硅藻指数远不止本文所使用的 4 种, 但是这 4 种硅藻指数包含了绝大多数的硅藻种类, 且 相关性较高. 最新版本的 IPS 指数包含了 4590 种硅藻 (包括变种), IBD 指数构建于法国,采取 1977-1994 年 949 个断面上的硅藻数据, IBD、IPS 指数也比较适合于评价我国的河流,本研究中 IPS 和 IBD 之间的相关 性达到了 0.937. 邓培雁等 ${ }^{[25]}$ 研究发现相对于其它硅藻指数而言, IPS、IBD 更适合于东江的水质评估, 赵湘 桂等 ${ }^{[26]}$ 利用 Van Dam 生态类群, 通过 IBD、IPS 指数对漓江的水质进行了较全面的评价; 与 IPS、IBD 显著相 关的指数 $I D G$ 为硅藻属指数,鉴定硅藻只需要鉴定到属, 采用此指数进行分析可以减少鉴定工作量, 虽然 $I P S 、 I B D 、 I D G$ 的建立都是基于法国河流硅藻数据,在其他国家的流域得到了很好的应用 ${ }^{[27-29]}$,但是国内使 用较多的仍为前两种 ${ }^{[30]}$. TDI 为硅藻富营养化指数, 主要根植于英国的河流, 发展至今已有三版, 能有效的 评估英国河流的富营养化状态 ${ }^{[3]}$, 但却不适合评价其他国家的河流 ${ }^{[31]}$, 在本文中, TDI 在群落的箱型图分布 中也没有表现出合理的变化趋势.

\section{4 结论}

1) TWINSPAN 数量分类和 DCA 排序两种方法结合很好地划分了硅藻群落: 群落 I 的主要优势种为清 
洁指示种, 群落 III 、 IV 的主要优势种为富营养化和有机污染指示种, 群落 II 为群落 I 和 III 、 IV 的过渡群落.

2) 贺江流域 4 组硅藻群落的分布表明:贺江流域上游和下游与西江的交汇处污染以及破坏较少, 水生 态质量保持良好; 贺江干流水质状况普遍低于支流 (马尾河除外) ; 人为干扰对河流生态质量影响很大, 马尾 河支流到合面狮大坝这一段水域,采矿以及电站的修建,使得营养盐以及污染物富集.

3 ) 硅藻指数评价中, $I P S 、 I B D 、 I D G$ 适合评价贺江流域河流生物质量.

\section{5 参考文献}

[ 1 ] 何 琦, 韦桂峰, 刘 静等. 增江底栖硅藻种类多样性及分布特征. 热带亚热带植物学报,2011,19(3):245-253.

[ 2 ] Coste M, Boutry S, Tison-Rosebery J et al. Improvements of the Biological Diatom Index(BDI) : Description and efficiency of the new version( BDI-2006). Ecological Indicators, 2009,9: 621-650.

[ 3 ] Kelly MG. Use of the trophic diatom index to monitor eutrophication in rivers. Water Research, 1998,32 : 236-242.

[ 4 ] Cemagref. Etude des methods biologiques d'appréciation quantitative de la qualité des eaux. Rapport Q. E. Lyon. Lyon: Agence de l'eau Rhone-Méditerranée-Corse-Cemagref, 1982.

[ 5 ] Coste M, Ayphassorho H. Tude de la qualitédes eaux du Bassin Artois-Picardie àl'aide des communautés de diatomées benthiques (application des indices diatomiques). Rapport Cemagref. Douai: Bordeaux-Agence de l'Eau ArtoisPicardie, 1991.

[ 6 ] Passy SI, Bode RW. Diatom model affinity (DMA), a new index for water quality assessment. Hydrobiologia, $2004, \mathbf{5 2 4}$ : 241-251.

[ 7 ] Krammer K, Lange-Bertalot H. Bacillariophyceae. Berlin: Spektrum Akademischer Verlag GmbH Heidelberg, 2000.

[8] 齐雨藻. 中国淡水藻志 (第四卷) - 硅藻门 · 中心纲. 北京:科学出版社, 1995: 1-89.

[9] 齐雨藻, 李家英, 谢淑琦等. 中国淡水藻志 (第十卷) - 硅藻门 ·羽纹纲. 北京:科学出版社, 2004: 1-130.

[10] Van Dam H, Mertens A, Sinkeldam J. A coded checklist and ecological indicator values of freshwater diatoms from the Netherlands. Netherlands Journal of Aquatic Ecology, 1994,28(1) :117-133.

[11] Fore SL, Grafe C. Using diatoms to assess the biological condition of large rivers in Idaho( USA). Freshwater Biology, $2002,47: 2015-2037$.

[12] Urrea G, Sabater S. Epilithic diatom assemblages and their relationship to environmental characteristics in an agricultural watershed( Guadiana River, SW Spain). Ecological Indicators, 2009,9:693-703.

[13] Biinn DW, Bailey PCE. Land-use influence on stream water quality and diatom communities in Victoria, Australia: a response to secondary salinization. Hydrobiologia, 2001,466:231-244.

[14] 赵孟绪,林秋奇,章 群等. 广东石岩、大镜山和大水桥三座水库的富营养现状. 生态科学, 2002,21(4):333-337.

[15] 刘景红,张 晟,陈玉成等. 重庆市水库富营养化调查及评价. 水土保持学报,2005,19(4):131-134.

[16] 再祥滨,姚庆祯, 巩 瑶等. 蓄水前后三峡水库营养盐收支计算. 水生态学杂志, 2009,2(2):2-7.

[17] 裴国凤,刘梅芳. 武汉东湖底栖藻类在不同基质上生长的比较. 湖泊科学,2009,21(3):357-362.

[18］苏日古嘎,张金屯,张 斌等. 松山自然保护区森林群落的数量分类和排序. 生态学报,2010,30(10):2621-2629.

[19] Urrea G, Sabater S. Epilithic diatom assemblages and their relationship to environmental characteristics in an agricultural watershed(Guadiana River, SW Spain). Ecological Indicators, 2009 ,9: 693-703.

[20] Leira M, Sabater S. Diatom assemblages distribution in catalan rivers, NE Spain, in relation to chemical and physiographical factors. Water Research, $2005,39: 73-82$.

[21] Pan Y, Stevenson RJ. Spatial patterns and ecological determinants of benthic algal assemblages in mid-Atlantic streams, USA. Journal of Phycology, 1999,35:460-468.

[22] Pan YD, Hill BH, Husby P et al. Relationship between environmental variables and benthic diatom assemblages in California Central Valley stream(USA). Hydrobiologia, 2006,561:119-130.

[23] Tang T, Cai QH, Liu JK. Using epilithic diatom communities to assess ecological condition of Xiangxi River system. Environmental Monitoring and Assessment, $2006,112: 347-361$.

[24] 邓培雁,雷远达,刘 威等. 桂江流域附生硅藻群落特征及影响因素.生态学报,2012,32(7):2196-2203.

[25] 邓培雁,雷远达, 刘 威等. 七项河流附着硅藻指数在东江的适用性评估. 生态学报,2012,32(16):5014-5024.

[26] 赵湘桂, 蔡德所, 刘 威等. 漓江水质硅藻生物监测方法研究. 广西师范大学学报: 自然科学版, 2009, 27 (2): 
142-147.

[27] Kwandrans J, Eloranta P, Kawecka B et al. Use of benthic diatom communities to evaluate water quality in rivers of southern Poland. Journal of Applied Phycology, 1998,10:193-201.

[28] Goma J, Ortiz R. Water quality evaluation in Catalonian Mediterranean rivers using epilithic diatoms as bioindicators. Vie et Milieu-Life and Environment, 2004,54:81-90.

[29] Blanco S, Becares E. Comparison of biotic indices for water quality diagnosis in the Duero Basin (Spain). Archiv fuer Hydrobiologie Supplement Large Rivers, 2007 ,17:267-286.

[30］李钟群,袁 刚, 郝晓伟等. 浙江金华江支流白沙溪水质硅藻生物监测方法. 湖泊科学,2012,24(3):436-442.

[31] Wu JT, Kow LT. Application of a generic index for diatom assemblage to monitor pollution in the tropical River Tsanwun, Taiwan. Journal of Applied Phycology, 2002,14:63-69. 